\title{
ANTROPOLOGÍA FILOSÓFICA Y ANTROPOLOGÍA TRASCENDENTAL
}

\author{
Francisco Rodríguez Valls \\ Universidad de Sevilla
}

\begin{abstract}
Resumen: Este escrito desarrolla el horizonte teórico del libro Orígenes del hombre con el propósito de responder y evaluar las críticas realizadas por los autores que componen este volumen.

Palabras clave: Antropología, ser humano, persona.

Philosophical Anthropology and Trascendental Anthropology.

Abstract: This paper develops the theoretical horizon of the book Origins of man with the purpose of responding and evaluating the criticisms made by the authors that compose this volume.

Keywords: Anthropology, human being, person.

Recibido: 30/11/2019. Aprobado:16/12/2019.

—Quien habla solo espera hablar a Dios un día.
\end{abstract}

"Es de bien nacidos ser agradecidos", así reza el refrán castellano. Deseo empezar con mi agradecimiento, porque sin la labor de Fernando Fernández al frente de AEDOS no hubiera sido posible este volumen. Ha propiciado el encuentro entre colegas, que se lean, que nos reunamos para dialogar y, por último, escribir cada uno sus conclusiones. No suele ser común que nos leamos entre cercanos y, menos aún, dedicar una sola línea a alguien con el que podemos contactar cuando nos parezca bien. Mi gratitud a todos los que asistieron al encuentro de Madrid y, de manera muy especial, a los ponentes y a todos aquellos que, finalmente, han dedicado un tiempo precioso a escribir sus comentarios.

Valoro especialmente las críticas que se me han hecho y la presentación de puntos de vista muy diferentes de aquel al que se asoma Orígenes del hombre. Todas son justas y esos puntos de vista complementan el libro objeto de debate. Voy a ampliar — aunque con ideas todavía muy germinales- 
su perspectiva teórica, desarrollando la complementariedad entre la Antropología Filosófica y la Antropología Trascendental, porque muchas de las aportaciones críticas van en esa línea y creo que mi posición se entenderá mejor si así lo hago. Mi libro forma parte de la Antropología Filosófica y se mueve en su horizonte, no rechaza la Antropología Trascendental, pero todavía no ha llegado a ella, no la desarrolla porque corresponde a un momento teórico posterior en el que se han despejado las dudas sobre la "especificidad" humana. La Antropología Filosófica llega hasta el establecimiento de la singularidad humana y lo hace apoyándose en los datos de la ciencia natural y social. La Trascendental parte de la especificidad y la estudia como tal.

No voy a responder uno tras otro a los escritos de mis colegas porque no quiero un ajuste de cuentas, sino contribuir a un mejor conocimiento de la Antropología en particular. Y en ello estamos todos implicados. El texto que presento no es un ejercicio ni de polémica ni de irenismo, tiene como objeto detallar algo más el ámbito de comprensión desde donde está escrito Orígenes del hombre.

\section{1.- El marco teórico de la Antropología Filosófica}

El nacimiento de la Antropología Filosófica está muy relacionado con la obra El puesto del hombre en el cosmos de Max Scheler. Su misión es ver cómo apareció la especie homo sapiens y estudiar cuáles son sus dimensiones. En esas tareas está señalar la diferencia —y semejanza- con el resto de los seres vivos, especialmente con aquellos que le están más cercanos. La Antropología Filosófica estudia al ser humano, hombre y mujer, en tanto que perteneciente a una especie biológica que encierra características especiales respecto de las demás. Tan especiales como tenerse a sí mismo como objeto de estudio y el haber llegado en las últimas decenas de años a darse cuenta de que el futuro del planeta Tierra está en sus manos. Para llegar ahí ha hecho falta que haya pasado por tres denominaciones culturales, dentro de la misma especie biológica, que enuncio con brevedad. 
Antropología filosófica y antropología trascendental

En primer lugar, la configuración del homo sapiens. Debido a su condición corporal inespecífica y abierta es, sobre todo, un animal de posibilidades. Posibilidades que tiene que gestionar conscientemente para llevarlas a realidad. El sapiens conoce el mundo objetivamente, va más allá de establecer solo relaciones subjetivas con la realidad del tipo "me gusta" o "no me gusta". El sapiens puede dar razón y describir el mundo y buscar sus causas. Durante parte de su historia fue, sobre todo, contemplador y admirador del Universo. Aquel que se extasiaba al descubrir el orden del mundo.

Con la técnica se adaptó al mundo y pudo adaptar el mundo a él, transformarlo conforme a sus propios criterios. Eso determinó culturalmente el paso del sapiens al homo faber. Su sabiduría por causas la aplicó en transformar la naturaleza, en separarse de ella creando mediaciones culturales que, a su vez, generaban nuevas necesidades que requerían más técnica para satisfacerse. El sapiens fabricó tanto que se hizo principalmente fabricante dejando la contemplación y puso el saber al servicio de la producción de cultura. Acabó por vivir en mundos artificiales donde lo natural era un reducto permitido por la voluntad humana: se erradicó la selva y el mundo se transformó en jardín.

El tercer paso tiene que ver con la destrucción del equilibrio natural por parte de la técnica y, sobre todo, cuando nos dimos cuenta de que el jardín se convierte en basurero y peligra la supervivencia no solo de la especie sino del planeta mismo. Es una conciencia de preocupación universal que hace pasar del homo faber al homo curans u homo curator. La necesidad de cuidar surge como experiencia emocional e intelectual ante la debilidad del otro y su requerimiento - tácito o expreso- de ayuda. Es una experiencia del poder que se inclina ante el débil para auxiliarlo y servirlo. Y el planeta en su conjunto necesita de esa ayuda.

Lo propio de lo humano es una categoría cuya preocupación coincide con los límites mismos de la realidad: si el sapiens conoce y el faber construye, el curator hace posible el crecimiento de todo protegiendo y amparando. Utiliza el conocimiento y la técnica no para sobrevivir o vivir bien sino para 
garantizar la vida y el bienestar de la totalidad del planeta. Con el sapiens, el planeta pasó a ser mundo. Con el faber, el mundo pasó a ser casa del ser humano. Con el curator, la casa pasa a ser hogar de todos. Que reconozca el valor de todo lo real pone al ser humano en una especial situación respecto del Universo: el humano está en condiciones de administrar como padre y no como tirano. En eso podemos establecer su especial valor o dignidad: el sapiens conoce todas las cosas, el faber las transforma todas, el curator las cuida todas y permite que lleguen hasta su máxima expresión de realidad. Con ello encontramos lo propio humano en su diferencia con el resto de los seres. Ello nos hace pasar a verlo desde otro punto de vista ontológicamente más sugerente y especulativo.

\section{2.- El marco teórico de la Antropología Trascendental}

La Antropología Trascendental rompe los límites de sujeción de lo humano a una especie biológica y lo refiere a la noción de persona. En teoría podría haber personas que no pertenecieran a la especie homo sapiens. En Orígenes del hombre se sostiene la hipótesis de que lo humano no empieza ni acaba en nosotros: hay personas en la evolución del sapiens y puede haberlas en estratos ontológicos iguales o superiores.

Se sostiene que hay personas antes del sapiens. Denominar homo a un género y no limitarlo a una especie implica la ampliación de lo humano, de lo estrictamente homo sapiens, comprenderlo más allá de un concreto biológico que ha aparecido demasiado frecuentemente como algo demasiado nuestro. No en el sapiens, sino ya en el habilis están presentes unos inicios de culturas que suponen la capacidad de ideación, la idea creadora que se lleva a la realidad y que no está contenida en los objetos naturales. La facultad que posibilita la ideación está operando ya desde el habilis y repercutiendo sobre su constitución morfológica posterior y aquella otra de las especies que le siguen: cultura y naturaleza forman un bucle de crecimiento y de transformación biológica. Es una de las formas en las que el 
Antropología filosófica y antropología trascendental

logos influye en la constitución de la corporalidad. Puede resultar controvertido afirmar que el habilis es persona, pero no considero que sea temerario entrar en ese debate.

Se sostiene que hay personas que convivieron con el sapiens. Parece que las características genéticas y culturales de varias especies de homínidos propiciaron el intercambio de mujeres, el de técnicas y el cultural. La utilización de técnicas de unos que son usadas por otros y la constatación de hibridación muestran casi como inapelable ese hecho. Cada vez se estudia más esta convivencia de lugar y de vida para la que se requiere una comunicación de alguna manera fluida. Sería un indicio que hay que tener en cuenta para argumentar acerca del carácter personal de otras especies, además del que posee el sapiens.

Se sostiene que, ontológicamente, ser humano y ser persona no coinciden: todo ser humano es persona, pero no toda persona tiene por qué ser un ser humano. La tradición filosófica ha atribuido el carácter de persona a los humanos, a las criaturas angélicas y a Dios. Otros filósofos amantes de la exobiología han atribuido esa característica también a posibles seres alienígenas con los que pudiéramos entablar un diálogo racional. El campo es amplio y nos enfrenta a la noción de persona y nos remite a algo mayor que el homo sapiens. En ese descubrimiento acaba la Antropología Filosófica y empieza la Trascendental, a la que sería mejor llamar, con un neologismo que no veo demasiado elegante, "personalogía": teoría de la persona. Ambas antropologías tienen objetivos diferentes, aunque coincidan en parte del camino. Pero no deben confundirse y hay que reconocer sus particulares idiosincrasias: el homo sapiens como persona es diferente como tal de un alienígena con dotación genética o base química distinta, de un ángel o de cualquiera de las personas divinas. Aquello de lo que se ocupa el personalismo no es del homo sapiens sino de la persona, concepto mucho más amplio que el horizonte de lo humano. Eso entraña categorías nuevas que trascienden lo meramente empírico y se centran en la trascendencia y en la 
espiritualidad del ser humano. Hace que se alejen del lenguaje de las ciencias naturales y se adentren en otros más fenomenológicos que insisten tanto en el don como en la intersubjetividad.

\section{3.- Antropologías e interdisciplinariedad}

Uno de los objetivos de la obra Orígenes del hombre es descubrir lo humano recogiendo lo que sobre ello se sabe en las diferentes disciplinas naturales y sociales y elaborando una síntesis filosófica a posteriori. Conocer lo humano significa conocer el dato humano y elaborar interpretaciones que se adecuen a ese saber. Para ello, para no imaginar en exceso, es necesario entrar en diálogo con las otras disciplinas para conocer lo que ellas saben. A eso se le suele dar el nombre de diálogo interdisciplinar. El término diálogo es esencial a la interdisciplinariedad, porque si no puede tergiversarse su naturaleza. A lo que se apela es al "diálogo" interdisciplinar y no a una "interdisciplinariedad" que apuntaría a que fuese asumida por personas que tuviesen el dominio de todas las disciplinas cuando el tiempo del saber universal en un solo hombre está ya lejos de ser posible. Cada uno sabe de lo suyo en tanto que especialista y tiene intereses en tanto que ser humano, pero apuntamos a un modelo de unidad del conocimiento que pueda alcanzarse con el trabajo de todos tomando los datos, diciendo cuáles están bien establecidos en cada disciplina y sobre ellos pensar en conjunto. Es un trabajo lento y difícil, pero más fructífero que cualquier otra forma de establecer conclusiones.

Separadamente, la antropología filosófica tiene el riesgo de quedarse en el dato establecido y no hacer interpretaciones de suficiente altura. También tiene un riesgo muy cercano de caer en el relativismo por no saber, quizás, moverse entre interpretaciones de mundos culturales muy diversos. Pero, por su parte, la antropología trascendental tiene el riesgo del exceso de especulación y de proponer un modelo de persona cegada por las limitaciones conceptuales de su propio mundo cultural. Es difícil hacerse una idea adecuada de lo humano sin un conocimiento amplio del hecho humano. No 
Antropología filosófica y antropología trascendental

nos vale un modelo exclusivamente a posteriori ni otro a priori. Tienen que estudiarse una a otra para solventar sus limitaciones: tienen que enseñarse una a otra; tienen que aprender una de otra. El diálogo interdisciplinar es también entre antropologías, va más allá de señalar las limitaciones, evidentes, de unas y otras para hacer el esfuerzo de una comprensión integra de lo humano.

\section{Conclusión}

El existente humano, que vive en el planeta, construye mundos y horizontes de comprensión particulares en los que puede vivir íntegramente sin necesidad de salirse de ellos. Se podría decir que, en muchos casos, el sujeto humano se limita a interpretar su existencia dentro de esos límites. Siendo eso fundamental, no es suficiente si lo unimos al deseo de conocer la realidad y de alcanzar la verdad que caracteriza al ser personal. Comprender y dar sentido a la vida de la forma más objetiva posible, evaluarla y proyectarla, forma parte necesaria de lo humano. A ello se le une, sin contradicción, la necesidad de realizarla de acuerdo con su autoría, con una decisión libre que proceda de lo más íntimo de su ser.

Evaluar la vida significa situarla donde se da: como natural y como creadora de cultura. Eso nos abre a múltiples dimensiones de lo humano. Y en ese afán de búsqueda de sentido se le abren objetos inmediatos pero insospechados: conocer en sí la naturaleza, descubrir las leyes que la rigen y que lo rigen a sí mismo en cuanto naturaleza y subjetividad. El propósito humano - en una posible dirección- es dar sentido al mundo para entender el suyo. La otra dirección necesaria es entenderse a sí mismo para transfigurar el mundo. La unidad del conocimiento es la unidad de vida del sujeto que vive en el conocimiento. En este contexto hay que hallar lo propio y específico de lo humano: como especie biológica y como persona. Las diversas dimensiones de su integración claman por una unidad de vida que en la historia ha estado ausente debido a los diferentes dualismos y pluralismos metafísicos. Tampoco los monismos radicales han sabido dar buena cuenta 
de la situación. Pocos pueden crear, muchos pueden saber, todos deben dar sentido a su vida.

La tesis con la que quiero concluir viene dada por la afirmación kantiana de que en la pregunta por el ser humano se resumen todas las otras. Interpreto esa afirmación de la siguiente forma: el ser humano necesita ver sentido para vivir, necesita dar sentido a su existencia. En la medida en que lo logra se le abren las puertas del resto de la realidad. También la de la realidad física para someterse a una recreación, a una transfiguración hecha por lo humano, que en estos tiempos se ha demostrado que tiene el límite del respeto a la condición de ser de cada cosa.

Francisco Rodríguez Valls rvalls@us.e 